\title{
Childlessness, parenthood and subjective wellbeing: The relevance of conceptualizing parenthood and childlessness as a continuum.
}

Marco Albertini, Political and Social Sciences, University of Bologna, Italy marco.albertini2@unibo.it

Bruno Arpino, Political and Social Sciences, Pompeu Fabra University, Spain bruno.arpino@upf.edu

Last Revision: October, 19th, 2018

\begin{abstract}
The objective of the paper is to show the theoretical and practical relevance of conceptualizing and operationalizing parenthood and childlessness as a continuum instead of a dichotomy - when evaluating the consequences of kinless-ness in later life. It is suggested that information on the number of children, structural and associational intergenerational solidarity can be utilized to operationalize the continuum. Subjective wellbeing is utilized as outcome of interest.

Data from waves 2, 4, 5 and 6 of the Survey of Health, Ageing and Retirement in Europe are used. The sample includes 183,545 respondents from 21 countries. Linear regression models with clustered standard errors are used.

Childless older individuals report lower levels of life satisfaction than parents. However, the largest difference is observed between those with one and two children. Using a measure of associational intergenerational solidarity to weight the degree of parenthood it is shown that parents who have infrequent contact with children report significantly lower levels of life satisfaction than childless individuals.

Kinless-ness is not only a demographic but also a social condition. When studying the consequences of ageing alone it is essential to consider not only the presence and "quantity" of kin, but also its "quality".
\end{abstract}

K-words: Childlessness; Parenthood; Kinless; Subjective wellbeing; Fertility; Europe 


\section{Introduction}

Ageing without kin has recently received considerable attention for its potential consequences on individuals' health and wellbeing (Margolis \& Verdery 2017; Verdery \& Margolis 2017). In Europe, among the different demographic shifts that contribute to a rising trend in the quota of older adults ageing alone, childlessness is one of the most prominent (Sobotka 2017).

The absence of children has been frequently associated, in popular culture and scientific research, with the risks of social isolation and loneliness in later life. Previous studies, however, have shown that the association between childlessness and individuals' wellbeing in old age varies considerably depending on the specific outcome considered, one's sociodemographic characteristics, life-course, and pathway to childlessness (Albertini \& Kohli 2017; Dykstra \& Hagestad 2007; Dykstra \& Keizer 2009). At the same time, most of previous studies have compared parents and non-parents as if parenthood/childlessness were two categories of a dichotomy. In the present paper, we propose to conceptualize this as a continuum and suggest that such a conceptualization allows for a better and more nuanced understanding of the consequences of ageing alone in later life. In particular, we combine information on the presence or absence of children with information on structural and associational intergenerational solidarity (Bengtson \& Roberts 1991) to show how the characteristics of parent-child relations may be utilized to operationalize the childlessparenthood continuum. Using subjective wellbeing (SWB) as the outcome of interest, we document that the presence and strength of intergenerational associational solidarity is a relevant factor to be taken into consideration when assessing the relation between different childlessness/parenthood statuses and individuals' wellbeing in later life.

\section{Childlessness: trends and consequences in later life}

\section{Childlessness trend in Europe}

The trend in childlessness rate among women born in Europe between 1900 and the mid 1970 s is U-shaped. After reaching its lowest level among women belonging to the 1935-45 birth cohorts, the number of childless women has been growing ever since. Despite the trend is leveling off in most Western European countries - and even reversing in a few cases - it is projected that in several countries and social groups up to one fourth of all women born in the second half of the 1970s will complete their reproductive life without having a natural child (Rowland 2007; Sobotka 2017; Tanturri et al. 2015). In a few decades these cohorts will enter later life and significantly change the social landscape of ageing population in Europe.

\section{Consequences of childlessness in later life}

The absence of children in later life has been found to be associated with a number of negative outcomes. The childless are often the target of social stigma, which in turn might be the cause of personal distress (Gillespie 2003; Park 2002). It has been found that nonparents tend to have smaller-size informal support networks and receive a lower amount of informal support with personal care than parents. The childless are also more likely to age alone, access formal care and health care services, and enter institutional care at lower levels of dependency and at a younger age than parents (Albertini \& Mencarini 2014; Dykstra 2006; Reher \& Requena 2017; Wenger 2009; Wu \& Pollard 1998). Moreover, non- 
parents have a lower life expectancy, partly due to their higher propensity to adopt unhealthy life styles (Umberson 1987; Weltof et al. 2004).

At the same time, despite often overlooked in previous studies, there are a number of dimensions along which older childless people perform similarly or significantly better than parents. For instance, non-parents enjoy similar or better psychological wellbeing than parents, with the partial exception of a higher risk of depression for childless women (Cheng et al. 2014; Dykstra 2015; Keith 1983; Nomaguchi \& Milkie 2003); when married, they enjoy a higher level of marital satisfaction (Twenge et al. 2003). Most importantly, previous studies have consistently documented that the childless are not more likely than parents to be socially isolated in later life (Wenger, 2009). They receive similar - or even a larger - amount of emotional support and help with household chores and paperwork than parents (Albertini \& Kohli 2017) and they provide support to others as much as parents or even with greater intensity (Albertini \& Kohli 2009; Hurd 2009).

A number of these findings, though, are not uniform across western societies and do not necessarily apply to all social groups or countries that have been investigated. As a matter of fact, not only the consequences of childlessness vary across different social contexts, birth-cohorts and depending on other relevant individual's socio-economic characteristics, but it has also been pointed out that what makes a huge difference - often more than being a parent or childless - are the different pathways that lead people to being without children in their later life (Dykstra \& Hagestad 2007; Dykstra \& Keizer 2009). How someone ends up being childless is often more important than not having children per se. Furthermore, it has also been shown that a similar distinction should also be applied to parents: the consequences of parenthood on specific outcomes in later life vary depending on the conditions of parenthood, or the "degree of parenthood".

\section{Parenthood, childlessness and subjective wellbeing}

The bidirectional relation between parenthood/childlessness and subjective wellbeing has increasingly attracted scholars' attention. On the one hand, there is evidence suggesting that higher levels of happiness and subjective wellbeing are correlated with higher probabilities of having a first child or progressing to higher parities (Aassve et al. 2012; Aassve et al. 2016; Margolis and Myrskylä, 2015). On the other hand, research on the effect of childbearing on individuals' subjective wellbeing has provided mixed findings. In general, it has been documented that the effect of becoming a parent on wellbeing varies depending on the institutional context, parent's marital history and gender, time since transition to parenthood has taken place, child's socio-economic situation and life course, child's parity and the specific dimension of subjective wellbeing taken into consideration (Aassve et al. 2012; Balbo \& Arpino 2016; Grundy et al. 2017; Hansen 2012; Huijts et al. 2013; Kohler et al. 2005). In addition, when comparing parents' and non-parents' wellbeing in later life in Europe, Hank and Wagner (2013) found that while partnership has a protective effect, childless individuals do not fare worse than parents. This finding is confirmed along a range of different measures of individual's psychological and social wellbeing. Similarly, studies in the US have documented the absence of a negative effect of childlessness on older individuals' subjective wellbeing, while showing the relevant role played by individual's sex and marital history (Koropeckyj-Cox 1998; Zhang \& Hayward 2001). 


\section{The heterogeneous effects of the absence/presence of children in later life: the childlessness /parenthood continuum}

Despite research adopting a life course approach has clearly shown that the absence of children in later life is the result of a huge variety of different paths (Hagestad \& Call 2007; Mynarska et al. 2015), what most of the studies of the effects of childlessness in later life have in common is that they operationalize childlessness and parenthood as a dichotomy: those who have never had children (or has survived their children) are classified as childless, all the others as parents. Further distinctions are sporadically introduced in the literature such as, for instance, that between different child parities, of between natural and step/adoptive parents.

Previous studies, however, have shown that not only the correlates of childlessness in later life vary across different societies, birth cohorts, social groups and depending on the specific domain/outcome considered, but also that what makes a huge difference are individual's marital history and, most importantly, the different pathways that lead older people to being without children (Dykstra \& Hagestad 2007; Dykstra \& Keizer 2009). Next, a similar distinction should be made for parents: the effects of making the transition to parenthood should be distinguished from those of playing the role of parent; being a natural or step parent makes a difference, too.

Thus, for instance, a review of these studies indicates that the absence of children might have different, even opposite, effects depending on individual's marital history. Graham (2015) shows that among elderly Australian women the absence of children is associated with worse health conditions than those experienced by mothers if childlessness is combined with divorce or widowhood; on the opposite, never-married childless women fare significantly better than mothers. Similarly, Keizer, Dykstra and Poortman (2010) in their study of the Netherlands found that marital history of fathers and childless men is an important factor moderating the effect of the absence/presence of children across different domains, with the socio-economic conditions of non-resident divorced fathers often resembling those of childless men. Maintaining contact and living proximity with adult children in later life versus loosing contact with them might also have a significant role in determining the effect of parenthood on individuals' wellbeing. Schnettler and Wöhler (2016) found that in Germany the characteristics of friendship and support networks of parents with no children living close to them are similar to those of the networks of childless people. Similarly, Albertini and Kohli (2017) reported that parents who have lost contact with their children are more similar to childless people than to other parents in terms of the likelihood of accessing formal care services in later life. Also, elderly fathers who have lost contact or live at great distance from their children - often as a consequence of a divorce in earlier life - are very similar to childless men in terms of the likelihood and intensity of informal social support received. Having children and their number may also indirectly influence older people subjective wellbeing through contacts with grandchildren (Arpino et al. 2018), which also depend on geographical proximity and contacts with children (see e.g., Hank and Buber 2009; Oppelaar and Dykstra 2004).

In light of these results from previous literature we suggest that empirical research focusing on the correlates of childlessness in later life - and more in general on the consequences of ageing alone - can benefit from conceptualizing parenthood and childlessness not as a dichotomy but as continuum. Furthermore, we suggest that even when the small number of cases available makes it difficult to distinguish different roads to childlessness - and thus, for instance, differentiating between natural parents, step ladoptive parents and parents who survived their children - measures of associational and 
structural intergenerational solidarity can be profitably utilized to locate individuals along a parenthood/childless continuum. This idea is illustrated in Figure 1 where at one extreme of the continuum we have childless and at the other extreme we have parents with many children who are all "close". Closeness is defined in this paper in terms of geographical proximity and frequency of contacts but it may be extended to other dimensions (e.g., emotional closeness).

More specifically and in light of previous studies, we hypothesize that, when analyzing individuals' subjective wellbeing as the outcome of interest: $(\mathrm{H} 1)$ considering the number of children is relevant to shed light on the heterogeneity within the parents' group. Parents with one child are more similar to non-parents than elderly parents with two, three or more children; (H2) Living close to and keeping regular contact with ones' adult children are significant dimensions of "being a parent" in later life. Thus, those parents who have infrequent contact with their children or live at a large distance from them are located closer to childless individuals than to other parents along the parenthood/childless continuum. In other words, we expect to observe that at the same parity, those parents who have no contact with their adult children or live at a great distance from them report a level of subjective wellbeing similar to that registered for non-parents. (H3) Finally, due to the matrifocal character of parent-children relations in Western societies and the central role of women as kin keepers (Rossi \& Rossi 1990; Chan \& Elder 2000), we expect that living far from children or losing contact with them is less frequent but more detrimental for mothers than fathers. Since it has been documented that the effect of the absence of children on individual's wellbeing varies according to the latter's sex, we will test this hypothesis by comparing the coefficients of separate regression models performed on the subsamples of male and female respondents, respectively.

Figure 1 - Graphical representation of the childlessness-parenthood continuum and its hypothesized association with subjective wellbeing

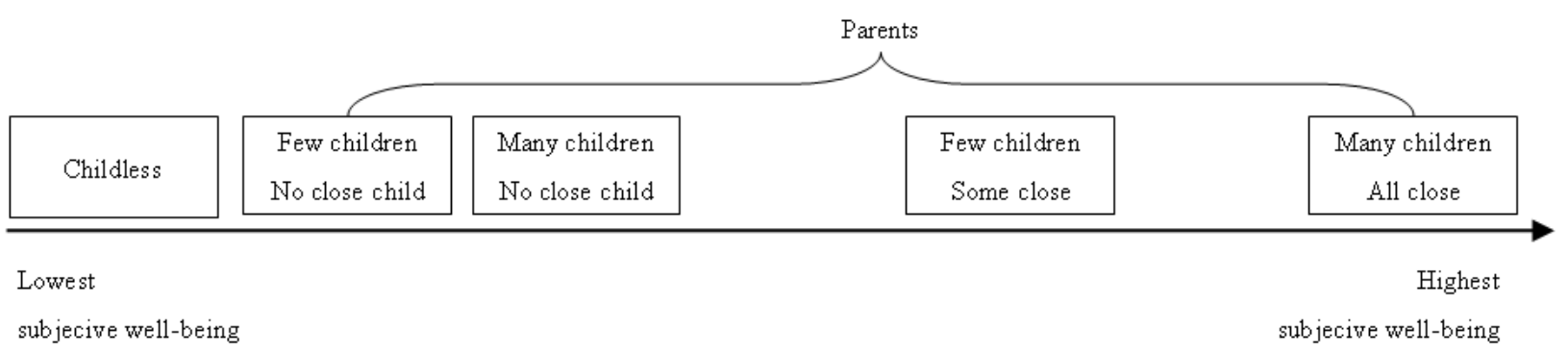

\section{Method}

\section{Data and Sample}

The empirical analyses presented below are based on data from the Survey of Health, Ageing and Retirement in Europe (SHARE). SHARE is a longitudinal, multidisciplinary, cross-national survey representative of the non-institutionalized population aged 50 and over in several European countries. During the interview, all persons aged at least 50 in the selected households were interviewed, as well as their partners independent of their age. SHARE includes detailed information of the physical and mental health of the respondents, their children and their relation with these children - e.g. geographical distance, frequency 
of contact, exchange of support. Since our focus here is on older parent's subjective wellbeing, the unit of analysis will be the individual respondent - and not the parent-child dyad.

The final sample includes respondents aged 50 years of more, who participated to at least one of the following waves of SHARE: second (2007), fourth (2011), fifth (2013) or sixth (2015). We exclude the first wave due to the fact that a different scale was utilized in the question utilized to generate our dependent variable, and we also exclude the third wave because it contains mainly retrospective information on the respondents. Our working sample includes 103,199 women and 80,346 men from 21 countries (Austria, Belgium, Croatia, Czech Republic, Denmark, Estonia, France, Germany, Greece, Hungary, Ireland, Israel, Italy, Luxembourg, Netherlands, Poland, Portugal, Slovenia, Spain, Sweden, and Switzerland).

\section{Dependent variable: subjective wellbeing}

Our dependent variable is life satisfaction measured on an 11-point scale ranging from 0 to 10. This is a standard item to measure life satisfaction. Life satisfaction is a valid measure of wellbeing, which contains substantial information about how individuals evaluate their lives (Diener et al. 2013) and has been extensively used as a measure of subjective wellbeing of older people (e.g., Arpino et al. 2018; Niedzwiedz et al. 2014).

\section{Independent variables}

Central to the aim of our paper is the definition of the main independent variable. Two different definitions of the main independent variable are adopted, to include both information on the number of living children a respondent has and, respectively, the geographical distance from them and frequency of contact with them. As for what regards living distance, we distinguish children who live "close" (within 25 kilometers) and those who do not. For those parents with more than one child we also distinguish between parents who have all, at least one, the majority or none of their children living close to them. Contacts in the SHARE questionnaire are defined broadly (in person, by phone or mail). We distinguish frequent contacts (at least weekly) from the less frequent interactions. Only frequent contacts are labeled as "contact". Again, we differentiate according to the fact that frequent contact is maintained with all, at least one, the majority or none of the children.

In all multivariate analyses we control for a set of variables that in previous studies have been found to be associated with older people subjective wellbeing and/or our explanatory variables of interest (Arpino et al. 2018; Hank 2007; Niedzwiedz et al. 2014). Sociodemographic control variables include: age (in 5-year categories); marital status (married or in partnership - reference, never married, divorced or widowed); education (low - reference, medium and high), total net household income (dummies for within wave and country deciles), employment status (working, retired - reference, other) and type of living area ("rural" =1 for respondents living in rural areas, =0 otherwise). We also control for several measures of health status. First, we consider information on the experience of chronic diseases reported in response to the question, "Has a doctor ever told you that you had any of the following conditions: Hypertension, diabetes, cancer, lung disease, heart disease, stroke and arthritis?" We include a dummy variable indicating whether the respondent reported at least one condition or not as control. Second, we control for limitations with activities of daily living. Finally, in all regression analyses we include dummies for the wave of the survey and countries. 
Methods \& analytic strategy

We estimate multivariate linear models with clustered standard errors to account for withinindividual correlation. Model 1 only includes a dummy variable indicating whether respondents have children or not. Model 2 distinguishes between those having 1, 2, 3 or more children (childless is the reference). Model 3 combines information on number of children and geographical distance with each child. Finally, model 4 combines information on number of children and frequency of contacts with each child.

We have implemented several additional analyses and robustness checks. First, to account for heterogeneity across countries we re-estimated all models by groups of countries. The pattern of results was similar in each group of countries with a few exceptions that we shall mention in the results section. Second, we used relative measures of geographical proximity and contacts based on whether geographical proximity or contacts were below the country median. Third, we also considered different thresholds to define geographical closeness (100 and 5 kilometers). Results of these robustness checks (available upon request) were similar to those presented here.

\section{Results}

Table 1 reports, by gender, the distribution of our explanatory variables (first two columns) and the average outcome (subjective wellbeing) for each category of the explanatory variable. About $11 \%$ of women and $13 \%$ of men in our sample are childless. Most of those who are parents have 2 children. Although the majority of parents have at least one child living close, $17.5 \%$ of all women and $18.2 \%$ of all men in our dataset have children but all of them live more than $25 \mathrm{~km}$ away. Similarly, $6.2 \%$ of all women and $8 \%$ of all men are parents but have less than weekly contacts with any of their children. Parents tend to report a higher subjective wellbeing than their childless counterparts, especially if they have at least 2 children. Geographical distance does not seem to display a clear association with SWB. Differently, parents who have infrequent contact with children tend to report lower levels of subjective wellbeing than their counterparts who enjoy frequent contacts with their children and also compared to childless. 
Table 1 - Descriptive statistics for the explanatory variables by gender and for dependent variable by gender and each category of the explanatory variables.

\begin{tabular}{lrrrr}
\hline & \%omen & \multicolumn{3}{c}{ Average subjective Wellbeing } \\
& 10.9 & 12.6 & 7.31 & 7.35 \\
\hline Childless & 89.1 & 87.4 & 7.52 & 7.68 \\
Parents & & & & \\
\hline Number of children & 16.2 & 14.2 & 7.29 & 7.48 \\
1 child & 39.7 & 40.2 & 7.55 & 7.70 \\
2 children & 33.1 & 33.1 & 7.58 & 7.72 \\
3+ children & & & & \\
\hline Number and geographical distance & 4.8 & 4.4 & 7.40 & 7.42 \\
1 child far & 7.8 & 8.5 & 7.67 & 7.73 \\
2 children - both far & 4.9 & 5.3 & 7.83 & 7.82 \\
3+ children - all far & 11.4 & 9.8 & 7.24 & 7.51 \\
1 child close & 14.0 & 13.5 & 7.54 & 7.71 \\
2 children - 1 close & 7.6 & 7.5 & 7.68 & 7.83 \\
3+ children - 1 close & 18.0 & 18.2 & 7.52 & 7.68 \\
2 children - both close & 11.5 & 11.1 & 7.52 & 7.68 \\
3+ children - most close & 9.2 & 9.1 & 7.45 & 7.63 \\
3+ children - all close & & & & 7.5 \\
\hline Number and contacts & 1.9 & 2.3 & 6.98 & 7.14 \\
1 child - no contact & 2.5 & 3.3 & 7.17 & 7.37 \\
2 children - no contact & 1.8 & 2.4 & 7.41 & 7.49 \\
3+ children - no contact & 14.3 & 12.0 & 7.33 & 7.55 \\
1 child - contact & 9.6 & 9.5 & 7.42 & 7.60 \\
2 children - 1 contact & 4.4 & 4.7 & 7.44 & 7.58 \\
3+ children - 1 contact & 27.6 & 27.3 & 7.63 & 7.78 \\
2 children - both contact & 11.9 & 11.5 & 7.48 & 7.68 \\
3+ children - most contact & 15.0 & 14.5 & 7.72 & 7.85 \\
3+ children - all contact & & & 7.49 & 7.63 \\
\hline Total & & & & \\
\hline
\end{tabular}

The results of the linear regression models, fitted separately by gender, are reported in Table 2. Country fixed effects and all control variables mentioned above are included but coefficients not shown for brevity (complete estimates are provided in Table S1 of the Supplementary Materials). As explained above, the four models differ as for what regards the definition of the main independent variable; childless always constitutes the reference category.

Results for model 1 clearly indicate that, ceteris paribus, elderly parents are more satisfied with their life than non-parents. The positive association between parenthood and individuals' wellbeing is statistically significant and its strength is similar for both women and men, i.e.: 0.17 and 0.13 points, respectively. When focusing on the social significance of these effects we should note that its size is apparently small. However, previous studies using the same or similar scales as outcome variable have interpreted effects of about 0.2 points as substantially important (see e.g. Boarini et al. 2012). This is because, although the life satisfaction scale ranges theoretically from 0 to 10 , most respondents report high values. 
In our sample, about $80 \%$ of respondents report a value between 6 and 10 . The substantive importance of the estimated coefficients for parenthood is also clear when we observe that other important determinants of SWB show similar effects. For example, the coefficients for high education (reference is low education) are 0.2 and 0.15 , those for the $5^{\text {th }}$ income decile (reference is first decile) are 0.23 and 0.13 for women and men, respectively (Table S1).

In line with our fist hypothesis, model 2 indicates that parent's SWB increases with the number of children. The largest difference is observed between parents with 2 children or 3 or more children compared to childless (coefficients range between .14 and .24). Instead, the difference between non-parents and parents with one child, and between parents with two children and those with three or more are very small. Also, the positive gradient of the association is slightly more accentuated for mothers than for fathers.

In model 3 we adopt a definition of parenthood that also includes information on the living distance between each respondent and their children - see description in the methods section. In general the results do not support our hypothesis that a greater living distance from one's adults children is associated with a lower level of subjective wellbeing. The number of children plays a greater role than where they live. At the same child parity parents who have their child(ren) living far from them show similar, or even higher, average levels of SWB than parents whose children live close-by. Also, in contrast to our third hypotheses there are no appreciable differences by gender.

While geographical closeness with children (structural solidarity) does not seem crucial in the relation between older Europeans' subjective wellbeing and parenthood, model 4 points to an important role of contacts with children (associational solidarity). Parents who have less than weekly contact with their children report a lower level of life satisfaction not only with respect to parents who contact children frequently, but also vis-à-vis childless individuals. This negative relation is clearer at lower child parities - i.e. the negative coefficients are smaller and not statistically significant for parents with three or more children and fathers with two children. These results not only confirm, in line with our second hypothesis, that low levels of intergenerational associational solidarity make parents more similar to childless individuals; but they also indicate that, from the point of view of elderly individuals' subjective wellbeing, being a parent but having infrequent contact with them is more detrimental that being childless per se. At the same time, our hypothesis that low associational solidarity is more consequential for mothers than fathers is only partially supported: coefficients tend to be smaller for fathers but differences are relatively small. 
Table 2 - Estimates of linear regression models predicting life satisfaction as a function of parenthood-related variables.

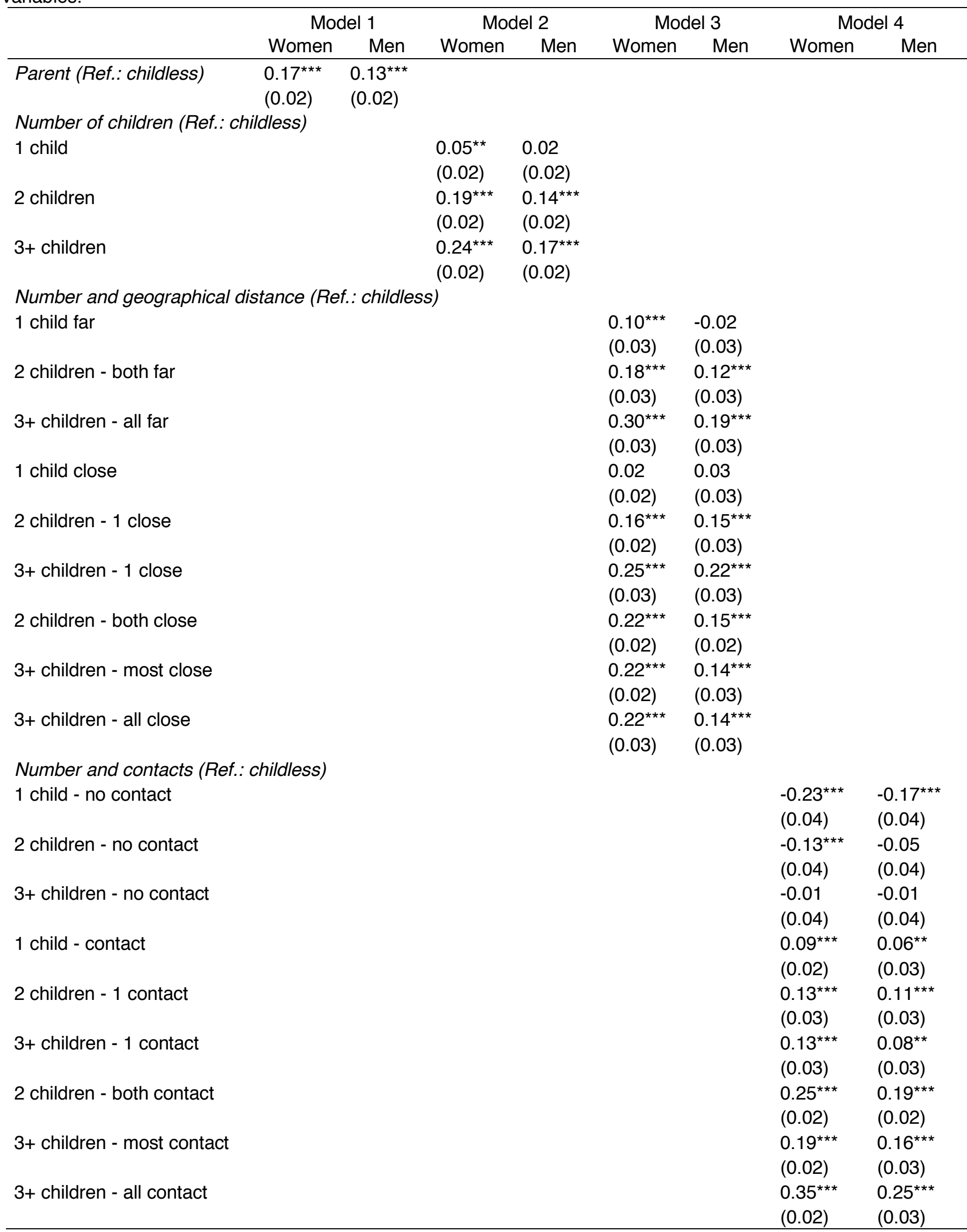

Notes: ${ }^{* \star *} p<0.01 ;{ }^{* *} p<0.05 ;{ }^{*} p<0.1$. Standard errors in parentheses. Control variables described in the text are included in all models. For respondents with 3 or more children "most" means 2 or more children. $\mathrm{N}=$ 103,199 (women) and 80,346 (men). 
To better appreciate our main findings from models 3 and 4 we used the estimated coefficients to predict the average SWB by gender and for each childless-parenthood category. Predicted values are displayed in Figure 2 together with confidence intervals for pairwise comparisons at the $5 \%$ significance level. In each graph, the categories of our explanatory variables are reported on the $y$-axis in ascending order by the average predicted SWB level. The two graphs on the left hand side of Figure 2 confirm that proximity between parents and their children is not meaningfully associated with parents' SWB. Categories in fact tend to be ranked by the number of children. Graphs on the right-hand side show the childless-parenthood ranking in terms of contacts. It is evident that contacts matter: all categories of parents who have infrequent contact with all their children are placed at the bottom of the ranking together with childless. When comparing parents with the same number of children, SWB is always higher for those who have at least weekly contact with them. For example, mothers of 2 children who have frequent contact with both of them are on average about 0.4 points more satisfied with their life than their counterparts who have infrequent contact with both children. The gap is similar but lower for fathers (0.24 points). These graphs also suggest that the number of children with whom parents are in contact matters more than the number of children per se. In fact, SWB of parents who have frequent contact with at least one child are similar irrespectively of the number of children they have $(1,2,3$ or more).

Figure 2 - Predicted subjective wellbeing by gender and measures of childless-parenthood (based on geographical distance or contacts)
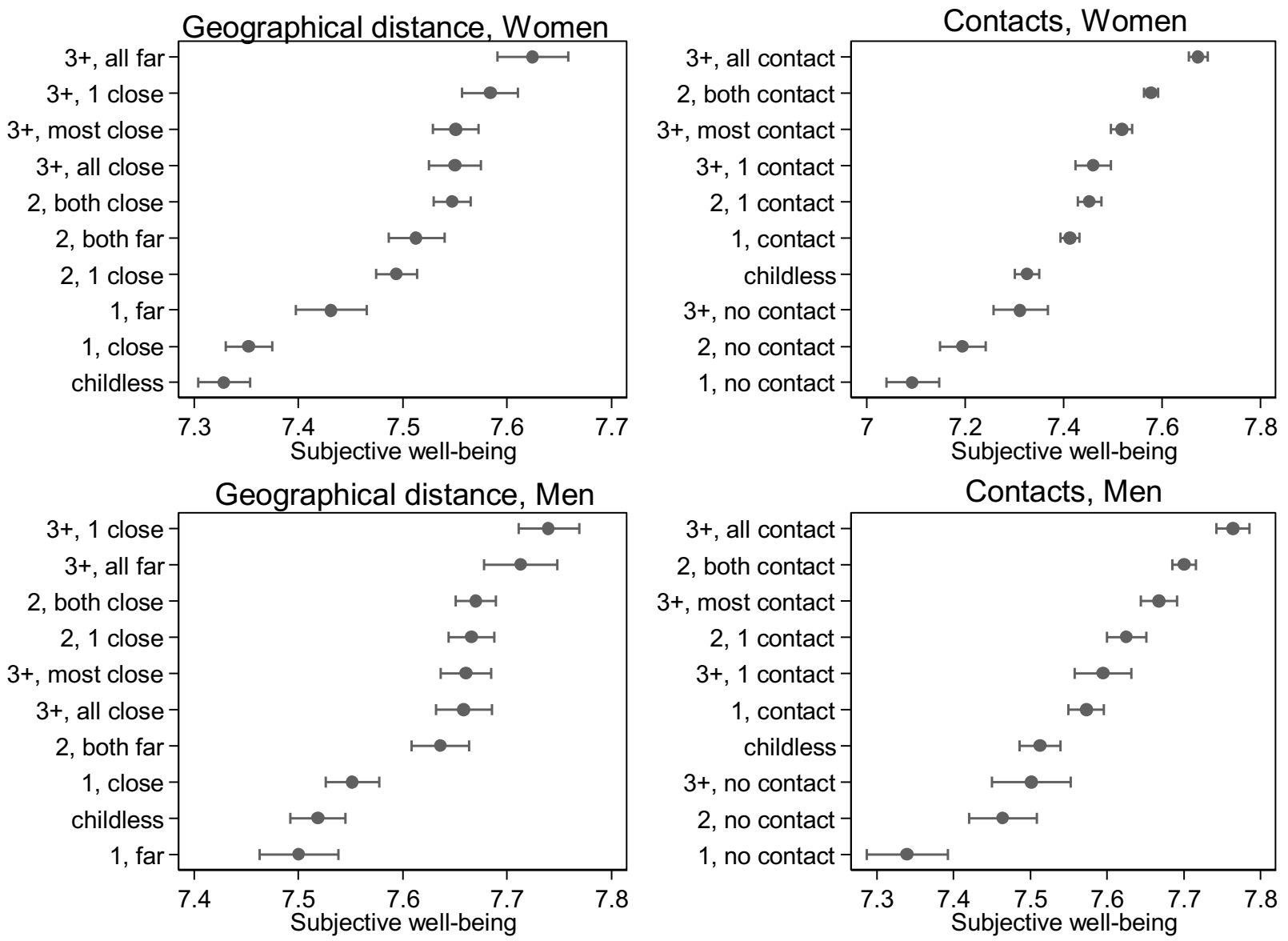

Note: Predictions refer to estimates obtained from models 3 (geographical distance) and 4 in Table 2. Predicted subjective wellbeing is displayed together with confidence intervals for pair-wise comparisons at $5 \%$ 
significance level (i.e., confidence intervals are centered on the predicted value and have lengths equal to $2 \times$ $1.39 \times$ standard errors to have an average level of $5 \%$ for the Type I error probability in the pair-wise comparisons).

\section{Discussion}

Similarly to what documented for the US (Margolis and Verdery 2017; Verdery and Margolis 2017), recent demographic changes in Europe may lead to a much larger number of kinlessness people among the future elderly population than we see today. The rapid increase of childlessness among women of the 1945-1875 birth cohorts is one key component of these demographic trends. Generally previous studies have reported negative correlates of childlessness in later life, but there are some important exceptions along various dimensions of individuals' wellbeing and social connectedness. Thus, for instance, it has been shown that among the currently childless elderly European population the risk of social isolation is not significantly higher than that found among parents and, also, that the likelihood of receiving informal social support is higher than that registered for parents.

Most of previous studies on the topic have treated parenthood and childlessness as a dichotomy. There is some evidence, though, that when considering older people's wellbeing there is significant heterogeneity within both the parents and childless group. In particular, this within-group heterogeneity is not only related with individuals' socio-economic characteristics such as educational or income levels, but also with (i) the different pathways to childlessness among the non-parents and (ii) the variation of the levels of structural, associational and functional intergenerational solidarity among parents. In line with this research we argue that studies on the consequences of ageing alone should conceptualize and operationalize childlessness and parenthood not as a dichotomy but as two poles of a continuum. As an example of the potentiality of this approach we investigated the advantages of using indicators of structural and associational solidarity, together with child parity, in developing a measure of the degree of parenthood when studying the relation between parenthood/childlessness and subjective wellbeing in later life.

When we treat parent and non-parents as two separate alternative groups we find that childless elderly Europeans report slightly lower levels of life satisfaction than parents. However, distinguishing different groups according to the number of children reveals that the largest difference in SWB is observed between those with 1 and 2 children and not - as one might have expected - between the non-parents and those with at least one child. In other words, at some points of the distribution, the number of children seems to be more consequential for elderly people's SWB than having or not children. A further distinction, made on the basis of parent-child living distance, did not lead to expected or easily interpretable results. This might suggest that in the European context structural solidarity is a poor indicator of the "degree of parenthood" in later life or that other measures of this dimension - such as time needed to reach one's child home (not available in SHARE data) - should be preferred. Differently when we take into consideration the intensity of intergenerational associational solidarity to "weight" the degree of parenthood in later life together with child parity - we obtain interesting findings. In this case adopting a continuum conceptualization leads us to uncover the relevant heterogeneity within the parents' group: parents with two or more children and who have regular, weekly contact with them fare significantly better than parents who have infrequent contact with them. Most importantly, adopting a "continuum approach" to the analysis of older parents/childless people's SWB we are able to show that those who age (formally) as parents but have infrequent contact with own adult children report significantly lower levels of life satisfaction than childless individuals. We can paraphrase this finding by saying that kinless-ness is not only, or 
necessarily, a demographic or biological condition but most importantly a social condition. In other words, among older Europeans being kinless or nor depends not only on yours, or your family's, demographic traits but also on the history and characteristics of your social relations - over and above parenthood and partnership status.

Our study paves the road to future research on outcomes of childlessness and parenthood in later life. This study can be expanded in several ways. First, we operationalize the childless-parenthood continuum in terms of closeness with children as measured by geographical proximity and contacts. Future studies may use alternative measures such as emotional closeness, normative solidarity, etc. Second, other dimensions of parenthood can be considered including the distinction between biological and adopted children. Third, the implications of the childless-parenthood continuum can be tested on outcomes other than subjective wellbeing on which we focused. What clearly emerges from our results, however, is that the consequences of ageing alone have to be understood not only in terms of presence or absence of kin, but also in terms of the quality of the relations with one's kin (and non-kin). Conceptualizing childlessness and parenthood as a continuum, in fact, is just a first step in the direction of systematically take into consideration not only information on the "quantity" of kin but also on its "quality" when studying the correlates of kinless-ness in later life.

\section{References}

Aassve, A., Arpino, B., \& Balbo, N. (2016). It takes two to tango: couples' happiness and childbearing. European Journal of Population, 32, 339-354. doi: 10.1007/s10680-0169385-1

Aassve, A., Goisis, A., \& Sironi, M. (2012). Happiness and childbearing across Europe. Social Indicator Research, 108, 65-86. doi: 10.1007/s11205-011-9866-x

Albertini, M., \& Kohli, M. (2017). Childlessness and intergenerational transfers in later life. In M. Kreyenfeld \& D. Konietzka (Eds.), Childlessness in Europe: Contexts, causes, and consequences. (pp. 351-368). Cham: Springer. doi: 10.1007/978-3-319-44667-7_17

Albertini, M., \& Kohli, M. (2009). What childless older people give: Is the generational link broken? Ageing \& Society, 29, 1261-1274. doi: 10.1017/S0144686X0999033X

Albertini, M., \& Mencarini, L. (2014). Childlessness and support networks in later life. New pressures on familistic welfare states? Journal of Family Issues, 35, 331-357. doi: 10.1177/0192513X12462537

Arpino, B., Bordone, V., \& Balbo, N. (2018) Grandparenting, education and subjective wellbeing of older Europeans. European Journal of Ageing. doi: 10.1007/s10433-0180467-2.

Balbo, N., \& Arpino, B. (2016). The role of family orientations in shaping the effect of fertility on subjective well-being: A propensity Score Matching Approach. Demography, 53, 955978. doi: 10.1007/s13524-016-0480-z

Bengtson, V.L., \& Roberts, R.E.L. (1991). Intergenerational solidarity in aging families: An example of formal theory construction. Journal of Marriage and Family, 53, 856-870. doi: $10.2307 / 352993$

Boarini, R., Comola M., Smith, C. Manchin, R., \& De Keulenaer, F. (2012). What makes for a better life? The determinants of subjective well-being in OECD countries. Evidence from the Gallup World Poll. OECD Statistics Working Papers, 2012/3. doi: 10.1787/5k9b9ltjm937-en

Chan, G.G., \& Elder, G.H. (2000). Matrilineal advantage in grandchild-grandparent relations. The Gerontologist, 40, 179-190. doi: 10.1093/geront/40.2.179 
Cheng, S.-T., Chan, W.S.T., Li, G.H.K., \& Leung, E.M.F. (2014). Childlessness and subjective well-being in Chinese widowed persons. The Journals of Gerontology: Series B: Psychological Sciences and Social Sciences, 69, 48-52. doi: 10.1093/geronb/gtb049

Diener, E., Inglehart, R., \& Tay, L. (2013). Theory and validity of life satisfaction scales. Social Indicator Research; 112, 497-527. doi: 10.1007/s11205-012-0076-y

Dykstra, P.A. (2006). Off the beaten track: Childlessness and social integration in later life. Research on Aging, 28, 749-767. doi: 10.1177/0164027506291745

Dykstra, P.A. (2015). Childless older adults. The Encyclopedia of Adulthood and Aging. doi: 10.1002/9781118521373.wbeaa204

Dykstra, P.A, \& Hagestad, G.O. (2007). Roads less taken: Developing a nuanced view of older adults without children. Journal of Family Issues, 28, 1275-1310. doi: $10.1177 / 0192513 \times 07303822$

Dykstra, P.A., \& Keizer, R. (2009). The well-being of childless men and fathers in mid-life. Ageing \& Society, 29, 1225-1240. doi: https://doi.org/10.1017/S0144686X08008374

Gillespie, R. (2003). Childfree and feminine: Understanding the gender identity of voluntary childless women. Gender \& Society, 17, 122-136. doi: 10.1177/0891243202238982

Graham, M. (2015). Is being childless detrimental to a woman's health and well-being across her life course? Women's Health Issues, 25, 176-184. doi: 10.1016/j.whi.2014.12.002

Grundy, E., van der Broek, T., \& Keenan, K. (2017). Number of children, partnership status, and later-life depression in Eastern and Western Europe. The Journals of Gerontology: Series B: Psychological Sciences and Social Sciences. doi: 10.1093/geronb/gbx050

Hagestad, G.O., \& Call, V.R.A. (2007). Pathways to childlessness: A life course perspective. Journal of Family Issues, 28, 1275-1310. doi: 10.1177/0192513X07303836

Hank, K. (2007). Proximity and contacts between older parents and their children: A European comparison. Journal of Marriage and Family, 69, 157-173. doi: 10.1111/j.17413737.2006.00351.x

Hank, K., \& Buber, I. (2009). Grandparents caring for their grandchildren. Findings from the 2004 survey of Health, Ageing, and retirement in Europe. Journal of Family Issues, 30, 53-73. doi: 10.1177/0192513X08322627

Hank, K., \& Wagner, M. (2013). Parenthood, marital status and well-being in later life: Evidence from SHARE. Social Indicators Research, 114, 639-653. doi: 10.1007/s11205012-0166-x

Hansen, T. (2012). Parenthood and happiness: a review of folk theories versus empirical evidence. Social Indicators Research, 108, 29-64. doi: 10.1007/s11205-011-9865-y

Huijts, T., Kraaykamp, G., \& Subramanian, S.V. (2013). Childlessness and psychological well-being in context: A multilevel study on 24 European countries. European Sociological Review, 29, 32-47. doi: 10.1093/esr/jcr037

Hurd, M. (2009). Inter-vivos giving by older people in the United States of America: Who received financial gifts from the childless? Ageing \& Society, 29, 1205-1224. doi: $10.1017 / \mathrm{S} 0144686 \times 08008362$

Keith, P.M. (1983). A comparison of the resources of parents and childless men and women in very old age. Family Relations, 32, 403-409. doi: 10.2307/584618

Keizer, R., Dykstra, P.A., \& Poortman A.-R. (2010). Life outcomes of childless men and fathers. European Sociological Review, 26, 1-15. doi: 10.1093/esr/jcn080

Kohler, H.-P., Behrman, J.R., \& Skytthe, A. (2005). Partner + children = Happiness? The effects of partnership and fertility on well-being. Population and Development Review, 31, 407-445. doi: 10.1111/j.1728-4457.2005.00078.x 
Koropeckyj-Cox, T. (1998). Loneliness and depression in middle and old age: Are the childless more vulnerable? The Journals of Gerontology: Series B: Psychological Sciences and Social Sciences, 53, 303-312. doi: 10.1093/geronb/53B.6.S303

Mynarska, M., Matysiak, A., Rybinska, A., Tocchioni, V. \& Vignoli, D. (2015). Diverse paths into childlessness over the life course. Advances in Life Course Research, 25, 35-48. doi: 10.1016/j.alcr.2015.05.003

Margolis, R., \& Myrskylä, M. (2015). Parental well-being surrounding first birth as a determinant of further parity progression. Demography, 52, 1147-1166. doi: 10.1007/s13524-015-0413-2

Nomaguchi, K.M., \& Milkie, M.A. (2003). Costs and rewards of children: The effects of becoming a parents on adults' lives. Journal of Marriage and Family, 65, 356-374. doi: 10.1111/j.1741-3737.2003.00356.x

Oppelaar, J., \& Dykstra, P. A. (2004). Contacts between grandparents and grandchildren. The Netherlands Journal of Social Sciences, 40, 91-113.

Park, K. (2002). Stigma management among the voluntary childless. Sociological Perspectives, 45, 21-45. doi: 10.1525/sop.2002.45.1.21

Margolis, R., \& Verdery, A. M. (2017). Older adults without close kin in the United States. The Journals of Gerontology: Series B: Psychological Sciences and Social Sciences, 72, 688-693. doi: 10.1093/geronb/gbx068

Niedzwiedz, C.L., Katikireddi, S.V., Pell, J.P., \& Mitchell, R. (2014). The association between life course socioeconomic position and life satisfaction in different welfare states: European comparative study of individuals in early old age. Age and Ageing, 43, 431436. doi: 10.1093/ageing/afu004

Reher, D., \& Requena, M. (2017). Elderly women living alone in Spain: The importance of having children. European Journal of Ageing, 14, 311-322. doi: 10.1007/s10433-0170415-6

Rossi, A., \& Rossi, P.H. (1990). Of human bonding. Parent-child relations across the life course. New York: Aldine de Gruyter.

Rowland, D.T. (2007). Historical trends in childlessness. Journal of Family Issues: 28, 1311 1337. doi: $10.1177 / 0192513 \times 07303823$

Schnettler, S., \& Wöhler, T. (2016). No children in later life, but more and better friends? Substitution mechanisms in the personal and support networks of parents and the childless in Germany. Ageing \& Society, 36, 1339-1363. doi: 10.1017/S0144686X15000197

Sobotka, T. (2017). Childessness in Europe: Reconstructing long-term trends among women born in 1900-1972. In M. Kreyenfeld \& D. Konietzka (Eds.), Childlessness in Europe: Contexts, causes, and consequences. (pp. 17-53). Cham: Springer. doi: 10.1007/978-3-319-44667-7_2

Tanturri, M.L., Mills, M., Rotkirch, A., Sobotka, T., Takacs, J., Miettinen, A., Faludi, C., Kantsa, V., \& Nasiri, D. (2015). State-of-the-art report. Childlessness in Europe. Families and Societies Working Paper Series, 32.

Twenge, J.M., Campbell, W.K., \& Foster, C.A. (2003). Parenthood and marital satisfaction: A meta-analytic review. Journal of Marriage and Family, 65, 574-583. doi: 10.1111/j.17413737.2003.00574.x

Umberson, D. (1987). Family status and health behaviors: Social control as a dimension of social integration. Journal of Health and Social Behaviour, 28, 306-319. doi: $10.2307 / 2136848$ 
Verdery, A. M., \& Margolis, R. (2017). Projections of white and black older adults without living kin in the United States, 2015 to 2060. Proceedings of the National Academy of Sciences, 114, 11109-11114. doi: 10.1073/pnas.1710341114

Weltoft, G.R., Bustrom, B., \& Rosen, M. (2004) Premature mortality among lone fathers and childless men. Social Science and Medicine, 59, 1449-1459. Doi: 10.1016/j.socscimed.2004.01.026

Wenger, C.G. (2009). Childlessness at the end of life: evidence from rural Wales. Ageing and Society, 29, 1241-1257. doi: 10.1017/S0144686X09008381

Wu, Z., \& Pollard, M.S. (1998). Social support among unmarried childless elderly persons. The Journals of Gerontology: Series B: Psychological Sciences and Social Sciences, 53B(6): S324-S335. doi: 10.1093/geronb/53B.6.S324

Zhang, Z., \& Hyward, M.D. (2001). Childlessness and the psychological well-being of older persons. The Journals of Gerontology: Series B: Psychological Sciences and Social Sciences, 56(5): S311-320. doi: 10.1093/geronb/56.5.S311 